\title{
Visual impairment in a woman with histiocytosis
}

\author{
Carlos Miret, Teresa Solé, Enric Pedrol, Juan A Junqué, Fernando Vázquez, Antonio
} Coca, Alvaro Urbano-Márquez

A 67-year-old woman was admitted because of a progressive impairment in her visual fields during the last six days, together with bilateral fronto-orbicular cephalea, particularly in the morning. In 1980 she had been diagnosed as suffering from diabetes insipidus. For this, she received chlorpropamide and clofibrate, and then inhaled desmopresine. A radiological study performed in 1986 because of pain in the left knee confirmed the existence of an osteolytic image at this level, together with lytic images in both iliac crests and the left scapula. Skin hyperpigmented lesions with thickening of the epidermis were detected in both legs, and the biopsy of one of these lesions also showed a typical histological pattern of histiocytosis. Treatment with etoposide and prednisolone was given, but had to be discontinued because of side-effects.

Physical examination showed red-violet skin lesions in the inferior right extremity. Ophthalmological examination showed a reduction of the visual fields and a bilateral papilledema. The rest of the examination was normal. A cranial magnetic resonance scan was performed (figures 1 and 2).

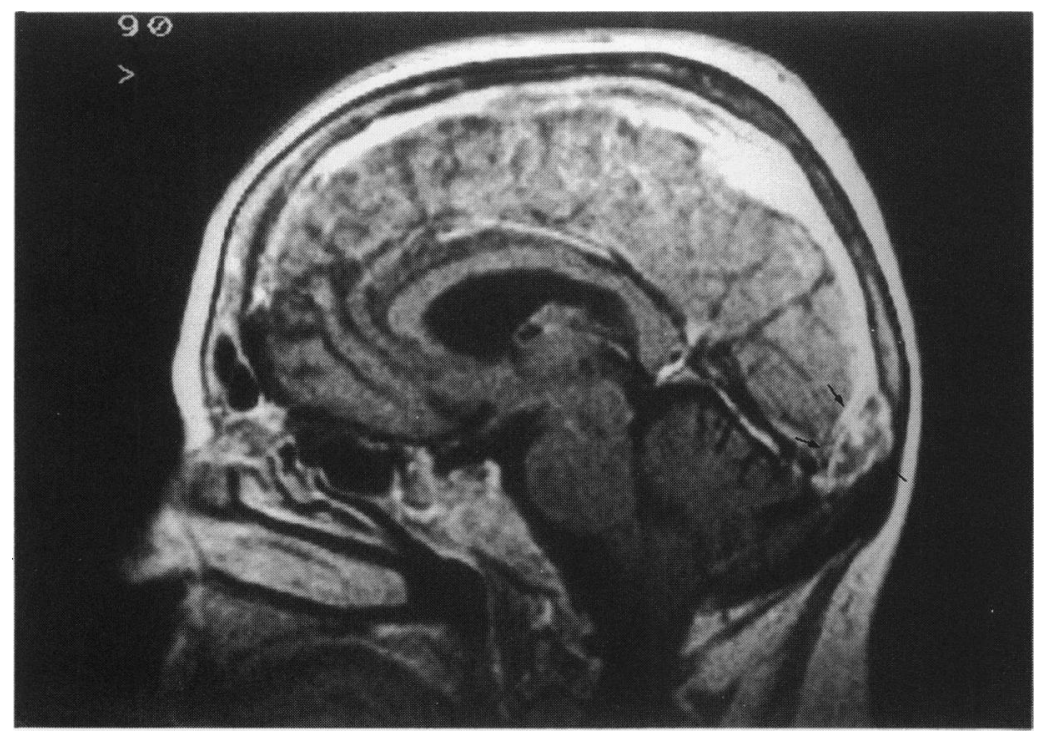

Figure 1

Hospital Clinic, School

of Medicine,

University of

Barcelona, Barcelona,

Spain

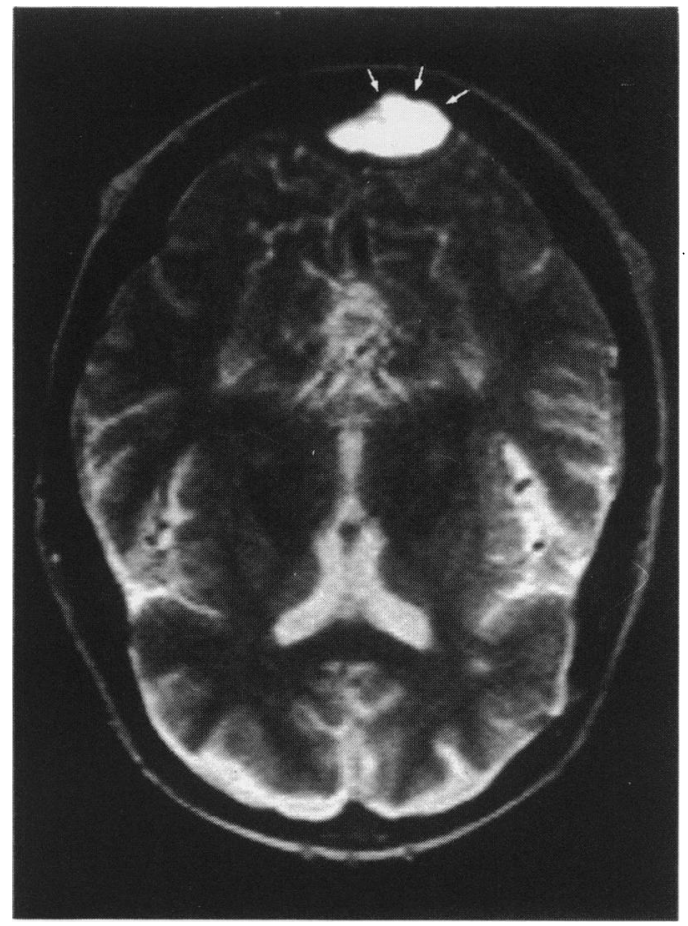

Department of

Figure 2

Internal Medicine

C Miret

E Pedrol

JA Junqué

A Coca

A Urbano-Márquez

Department of

Dermatology

T Solé

Department of

Radiology

F Vázquez

Correspondence to

Dr Enric Pedrol, Department

of Internal Medicine,

Hospital Clinic, Villarroel

170, 08036 Barcelona, Spain

\section{Questions}

1 Describe two abnormalities visible on these scans.

2 What is the most likely cause of this woman's visual impairment? 
Answers

QUESTION 1

(a) An extraparenchymatous image with mass effect in the occipital area, closely related to the confluens sinnum and situated in the epidural space, with lytic lesions in the inner table, enhancing heterogeneously (arrowheads).

(b) Prominent enhancement of the superior sagittal sinus area, with thickening and enhancement of the parasagittal meningeal coverings and the falx cerebri.

\section{QUESTION 2}

Thrombosis of the superior sagittal sinus vein, secondary to a leptomeningeal and sinus infiltration by Langerhans' cells.

\section{Discussion}

Until antibiotics were regularly used in clinical practice, thrombosis of the intracranial venous sinus was usually associated with septic complications from nearby cranial structures or infections of the paranasal sinus or the epidural and/or subdural spaces. Currently, aseptic thrombosis of the intracranial venous sinus has been reported in association with different processes such as vasculitis, tumours, traumatisms, puerperium or the use of oral contraceptives. ${ }^{1,2}$

The neurological complications arising from

1 Berry DH, Becton DL. Natural history of histiocytosis X. Haematol Oncol Clin N Am 1989; 1: 23-4.

2 Bousser MG, Chivas J, Bories J, Castaigne P. Cerebral venous thrombosis - a review of 38 cases. Stroke 1985; 16: 199-213.

3 Burn DJ, Watson JDG, Roddie M, Chu AC, Legg NJ, Frackowial SJ. Langerhans' cell histiocytosis and the nervous system. $\mathcal{f}$ Neurol 1992; 239: 345-50.
Neurological complications of histiocytosis

- diabetes insipidus: involvement of skull base

- deafness: infiltration of temporal bone

- blindness: infiltration of optic chiasm

- confusional syndromes, convulsive seizures, hydrocephalus, cerebellar syndrome: diffuse infiltration

Langerhans' cell histiocytosis are various (see box). ${ }^{3,4}$ Meningeal involvement may have an asymptomatic course, although focal seizures or intracranial hypertension caused by infiltration of dura may be present. ${ }^{3,5}$ Invasion of the venous sinuses due to leptomeningeal infiltration ${ }^{5}$ leading to thrombosis constitutes an exceptional complication. ${ }^{4}$ In fact, only one pediatric case has been reported involving thrombosis of the lateral sinus with secondary endocranial hypertension. ${ }^{4}$

\section{Final diagnosis}

Acute thrombosis of the superior sagittal sinus vein in Langerhans' cell histiocytosis.

Keywords: Langerhans' cell histiocytosis, superior sagittal sinus thrombosis

4 Jackson AH, Griffith JF. Histiocytosis $\mathrm{X}$ with benign intracranial hypertension. Dev Med Child Neurol 1975; 17: 783-7.

5 Enzmann DR. Inflammatory, non-infectious disease. In: Enzmann DR, ed Imaging of infections and inflammations of the central nervous system: computed tomography, ultrasound and nuclear magnetic resonance. New York: Raven Press, 1984; pp 318-24. 